\title{
The cultural eclecticism of globalism: perspectives from Russia
}

\author{
Oksana Ivanova ${ }^{1,3, *}$, Larisa Bilalova $^{2}$, and Ksenia Knyazeva $^{3}$ \\ ${ }^{1}$ Ufa State Pedagogical University named after M. Akmulla, 450008, 3a Oktiabrskoy Revolutsii str., \\ Ufa, Russia, \\ ${ }^{2}$ Bashkir State University, 452450, 59 Krasnoarmeyskaya str., Birsk, Russia. \\ ${ }^{3}$ Ufa State Petroleum Technical University, 450077, 100 Dostoevsky str., Ufa, Russia.
}

\begin{abstract}
The paper deals with the reflection of the processes of globalization and multiculturalism in the guise of modern cities. According to the authors of the article, graffiti is a purely urban phenomenon. Modern graffiti is a palette of emotions, feelings, expressive existence, peculiar to the young people, and the modern city is the focus of mad speeds. In this focus of speed collides the seething thirst for life of the youth and the phenomenon of alienation. The dialectic of this contradiction determines the emergence and development of graffiti as a form of self-expression shaped as street art, or as it is sometimes called, the underground art.

Graffiti as a component of street culture expresses the trends of globalization and its subjects, methods, and formats of performance: they are universal and do not have national peculiarities. In this case, the subject line of graffiti is a reflection of the specific features of culture, ideology, history, and traditions, that is, the mentality of a particular society. The authors of the paper present the lack of a single methodological, artistic and ideological orientation as cultural eclecticism. The article represents graffiti as a deviation, however, not as illegal acts but as an orientation of an individual to creative activity, as an act of self-actualization. In the study of graffiti as a socio-cultural phenomenon, parallels are drawn with the art of graffiti in various countries of the world, considering it as a form of multicultural integration. In modern interpretation, graffiti should be viewed as a kind of art, since it is artistic and aesthetic personal reflection of the personality, and creative form of its expression.

Graffiti as an extra-national and meta-social phenomenon is simultaneously a manifestation of universalism of the global socio-cultural tendencies, and an expression of eclecticism of the new forms of the modern city. The main cultural values are outside of time. Traditional values, modified and mutated, are updated in accordance with trends.
\end{abstract}

\section{Introduction}

Globalism as a concept is long and firmly established as the international lexical unit and the phenomenon of social life (Steger, 2010). Globalization and universalism are becoming

\footnotetext{
* Corresponding author: iom77@ rambler.ru
} 
characteristic features of modernity (Featherstone and Lash, 1995). If we consider globalization as a process leading to universal unity, then we interpret universalism as the method by which this trend is realized (Lagutina, 2014). In the context of this statement, as we have already written in the article "The principle of multiculturalism as the foundation of the new architecture of the Eurasian socium", there are significant social transformations ongoing in the society under contemporary conditions. Globalization of the world means a process of worldwide economic, political and cultural integration and unification. This is an objective process, systemic in nature, that is, it covers all spheres of society. As a result of globalization, the world becomes more tied up and more dependent on all its subjects (Ivanova et al., 2015). Formation of a single world economic space and necessary political interrelations objectively determine mutual cultural integration of countries and peoples. Identical forms of perception and representation of the world are invisibly and organically intertwined in national cultures, at times virtually disorienting the viewer. As an illustration, one can cite Eldar Ryazanov's film "The Irony of Fate, or With Easy Steam!", well-known to the Russian audience. Yet in the mid 70 -ies of the $20^{\text {th }}$ century, the filmmaker caught the tendency of universalism and artfully defeated it with humor: the architecture of large cities is so similar that, having got from one city to another, one cannot notice the difference in buildings. On the streets of a modern city, the concepts of universalism and inter-culture are manifested more clearly and systematically. Billboards, new buildings, architectural structures, that is, in a word, the image of the city is a reflection of major social changes. All that occurs in the society, and indeed in the world in general, sets the trends for the course of life, directs each sphere to a certain stage of existence.

Globalization is the key concept in our reflections. The transformation of the world into a stable and orderly system that has common characteristics is, in our view, one of the goals of globalization. From the standpoint of philosophy, we note that this process of unification is ambiguous. It has both a positive and negative impact on the state of society. After all, on the one hand, unification simplifies and facilitates the process of organizing social life, and, therefore, has a positive impact. On the other hand, it causes an association with boredom and monotony. And in this sense, unification, universalism and globalization, of course, have a negative connotation. However, globalization is not only a process, but also, in our view, is a complex mechanism that contributes to the development of a system of microsocieties, including the resolution of conflicts that are emerging within them (see, for example, Demakova et al., 2016). The maturing new comes into conflict with the old, losing actuality and social relevance. Conflict finds a way out in the birth of a new, that is, however, objectively related to the previous one. Modern Russian living conditions vividly illustrate this statement. Relatively calm, orderly life of Soviet people, different from the West European way, has now been replaced by the dynamics of the emergence of new scientific and ideological trends, the smooth reformatting of villages into cities and further into megacities and gigacities, the improvement of electronic means of communication, and the development of various technologies. All this are results of global social transformations. But this is not all. The boundaries of social transformations expand immeasurably, capturing such a social segment as culture. It is quite obvious that global processes no longer fit into a narrow framework. They require additional freedom, new sites, affecting different spheres of life. Even art suffers the inexorable power of globalization and changes its habitual appearance under its pressure. We have in mind, first of all, the change in the artistic appearance of modern Russian cities as a result of the development of so-called street art of graffiti. We would like to draw the attention of the reader to the fact that unlike the West European and American urban environment, the acquaintance of a wide Russian audience with the art of graffiti that filled the streets occurred only at the beginning of the $21^{\text {st }}$ century. We emphasize - the "wide acquaintance". Certainly, individual sketches and inscriptions were occasionally 
encountered earlier, but mass graffiti in the Russian architectural space is openly manifested at the beginning of the $21^{\text {st }}$ century.

Speaking about such an element of the contemporary artistic and architectural appearance of cities as graffiti, we would note quite active research interest in this phenomenon.

\section{Problem Statement}

How to treat graffiti, which fills today the architecture of modern Russian cities: as a structural element of art or as a deviation? How much does graffiti reflect the people's mentality? Can graffiti be viewed as a trend in the processes of globalization and multiculturalism?

\section{Research Questions}

\subsection{The art of graffiti as an eclectic image of a modern city}

According to the authors of the article, graffiti is a purely urban phenomenon. Modern graffiti is a palette of emotions, feelings, expressive existence, peculiar to the young people, and the modern city is the focus of mad speeds. In this focus of speed collides the seething thirst for life of the youth and the phenomenon of alienation. Dialectics of this contradiction determines the emergence and development of graffiti as a form of self-expression of street art, or as it is sometimes called, underground art. It manifests itself in everything: in subjects, technique of performance, forms of representation, etc. As a component of street culture, graffiti expresses the trends of globalization and its subjects, methods, and formats of performance: they are universal and do not have national characteristics. Wherein, the plot line of graffiti is a reflection of the specific features of culture, ideology, history, and traditions, that is, the mentality of a particular society. The authors of the article present the lack of a single methodological, artistic and ideological orientation as cultural eclecticism.

\subsection{Graffiti in modern Russia}

In contrast to the Western European and American urban environment, the wide Russian viewers' acquaintance with the art of graffiti that filled the streets occurred only at the beginning of the $21^{\text {st }}$ century, despite the fact that the phenomenon of graffiti was used historically, primarily in archaeological practice. In modern interpretation, graffiti should be viewed as a kind of art, since it is an artistic and aesthetic individual reflection of the personality and creative form of its expression.

\subsection{Graffiti is a form of deviation?}

Investigating graffiti of modern Russian cities, we noticed that the subjects, art methods, the style of graffiti are different: some are marked with a rather high artistic attractiveness; others balance on the brink of hooliganism and vandalism.

The authors present graffiti as a deviation, but not as illegal acts but as an orientation of the individual in creative activity, as an act of self-actualization. 
The main purpose of the research is the social and philosophical understanding of graffiti as a phenomenon of multiculturalism of the modern global community.

\section{Research Methods}

While working on the paper, the authors used a method of collecting and observing the actual material. They fixed graffiti, found in the city of the authors' residence, on the photo. The analysis of information on the topic, available in the Internet, allowed collecting data on the most characteristic features of graffiti in different countries of the world.

Socio-philosophical method allowed systematically comprehending research materials and drawing conclusions about the essence of graffiti and its place in modern culture.

\section{Findings}

While working on the article, the authors used a method of collecting and observing the actual material. They fixed graffiti, found in the city of the authors' residence, on the photo. The analysis of information on the topic, available in the Internet, allowed collecting data on the most characteristic features of graffiti in different countries of the world.

\subsection{The art of graffiti as an eclectic image of a modern city}

Walking around the city, we see numerous and masterpieces of street art, already popular today, and amazing in its scale and attracting the eye. All this is about graffiti and monumental painting. Graffiti has had a long history in the existence of mankind since the Neolithic era (Guthrie, 2005) and is a controversial subject, glorified by some, but hated by many (Keizer et al., 2008). Murals (frescoes) reflect many modern ideas that often have political goals (Lisle, 2006).

Graffiti is an element of American mass culture, which has already been thoroughly rooted in Russia, having absorbed the national Russian flavor. The spirit of globalization, which densely settles in culture, is manifested in such aspects. As a mirror, graffiti reflects the postmodern content of contemporary era, where, with an apparent identity, eclecticism reigns as a mixture of forms, methods, subjects, directions of social essence and existence (Gartus et al., 2015, Kolosov 2012). Identity is manifested in the fact that the street space is colorfully painted: walls of houses, fences, stairs, etc. Simultaneously, in the plot-role aspect, graffiti carries an imprint of social life of a particular society, its worries and aspirations. In Sao Paulo, Brazil, a rickety-looking kid looks at us from the wall of the building with an inscription beating the nerves: "NEED FOOD NOT FOOTBOOL" (20 Of The Best Cities To See Street Art, 2017). Bethlehem is a sacred place for Christians. On one of the buildings, there is a white dove with a laurel twig of the world in its beak, wideopen wings, in a flak jacket, where a red target is clearly seen as a silent and heartfelt call for peace (20 Of The Best Cities To See Street Art, 2017). 


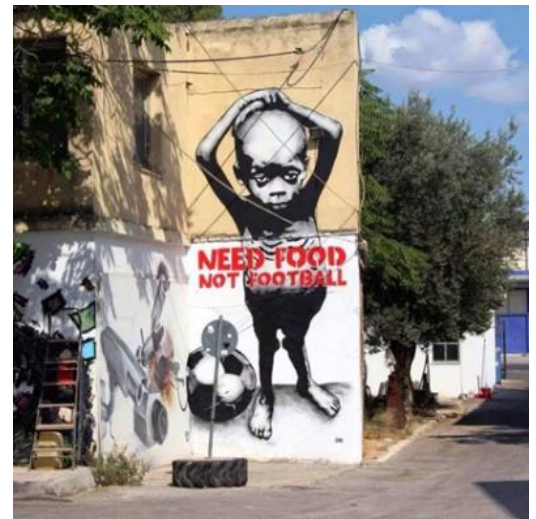

Fig. 1. Sao Paulo, Brazil.

Source: 20 Of The Best Cities To See Street Art, 2017 (http://www.earthporm.com/20-best-citiessee-street-art/).

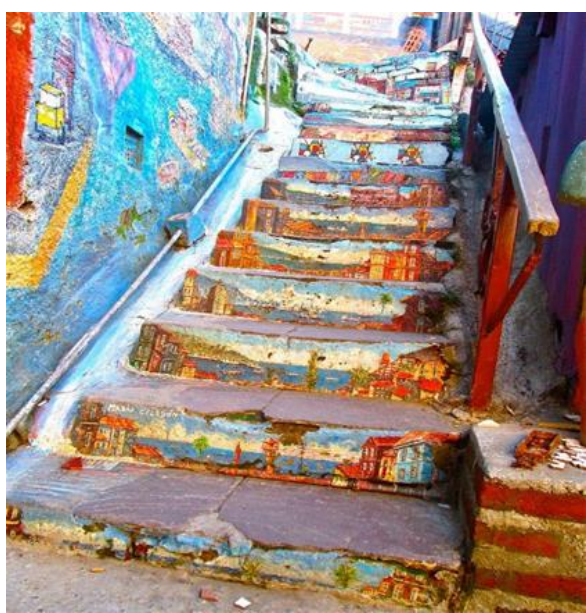

Fig. 3. Valparaiso, Chile.

Source: 20 Of The Best Cities To See Street Art, 2017 (http://www.earthporm.com/20-best-citiessee-street-art/).

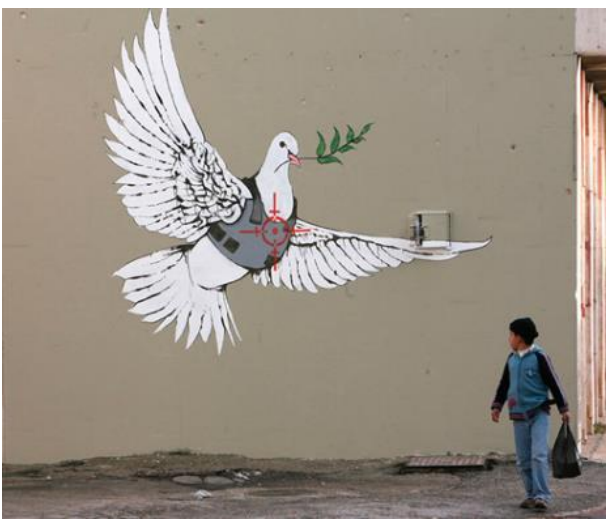

Fig. 2. Bethlehem, West Bank.

Source: 20 Of The Best Cities To See Street Art, 2017 (http://www.earthporm.com/20-best-citiessee-street-art/).

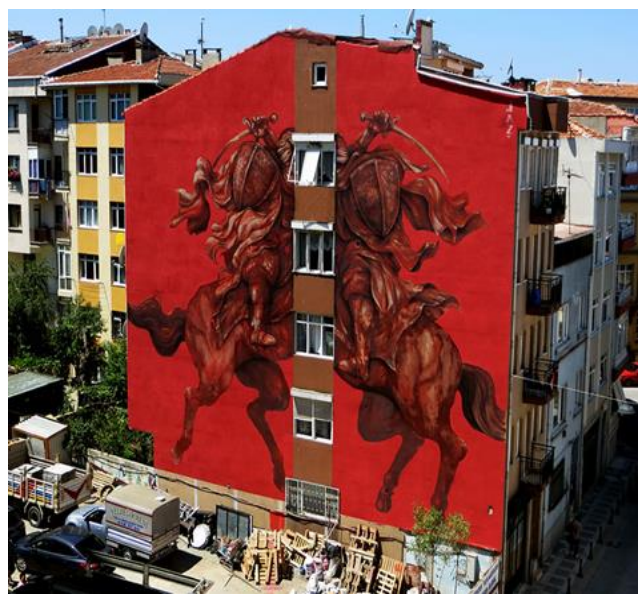

Fig. 4. Street Art-Istanbul, Turkey.

Source: 20 Of The Best Cities To See Street Art, 2017 (http://www.earthporm.com/20-best-citiessee-street-art/).

The national, juicy flavor of Chile and the recognizable morale of the Turkish East graffiti blurs the boundaries, becomes an integral part of urban architectural space around the world, reflecting the culture and mentality of people.

Is it possible to attribute graffiti to art? Tolstykh (2001) defines art as a form of creativity, "a method of spiritual self-realization of a person by sensually expressive means (sound, plasticity of body, drawing, word, color, light, natural material, etc.)". The above definition is fully applicable to the characterization of graffiti. Graffiti artists splash out on the urban plein air their inner self, their emotionally-felt breath of the surrounding world, calling for dialogue of those living nearby. In modern interpretation, graffiti should be viewed as a kind of art, since it is an artistic and aesthetic individual reflection of the personality, and creative form of its expression. 


\subsection{Graffiti in modern Russia}

In the Introduction, we noted that the word "graffiti" entered the broad Russian lexicon relatively recently, at the beginning of the $21^{\text {st }}$ century, although the concept of graffiti has been used for a long time in historical, in particular, archaeological, practice (Kolosov, 2012, Shaub, 2010). For example, Plavinsky (2013) understands a part of Old Russian iconography as graffiti. However, we are talking about changes in the appearance of modern Russian cities. Many cities in our vast country, like other cities in the world, such as Mexico, London, Prague, Lodz, etc., have graffiti as a form of artistic expression for various purposes, be it social advertising aimed at developing patriotism in civil society, propagation of any ideas and moral values, reminder of the role of compatriots in world history or creating a brand (style) of the city.

The graffiti art objects from Vyksa, one of small Russian cities (Central Russia region), where actual socio-cultural transformations are realized in the annual festival "Art-Ravine", can be referred as an example of modern Russian graffiti. The city, where in the recent past a metallurgical plant was the basis of its life and, accordingly, the architectural appearance, today, thanks to the annual festival, has turned into an exhibition of contemporary art in the open air. Witnesses say that "there is no, perhaps, nowhere else such concentration of art objects per kilometer of urban environment - graffiti on houses, sculptures in parks and on the streets, now also art rafts on the water" (Volkova, 2017).

Figure 5 June 17, 2017 in Vyksa, on the second day of the festival "Art- Ravine", the largest wall painting in Russia and Europe was opened on the facade of the OMK (United Metallurgical Company) plant. It is authored by the artist Misha Most. The area of the painting is 10 thousand square meters. Source: N. Volkova.

In the city of Perm, an interesting graffiti-fresco appeared in a public place. The artist created a drawing of the first Soviet cosmonaut Yuri Gagarin, who was hanged and crucified on the cross just like Jesus Christ. This controversial graffiti attracted attention of various media both in Russia and abroad.

Figure 6 Graffiti in Ufa (Hanging of Gagarin).

Each image carries in itself those tasks and information that are dictated by the time and needs of today. For the sake of simplicity, let us take a look at the walls of the buildings of our native Ufa and see how the globalization of art has manifested itself there.

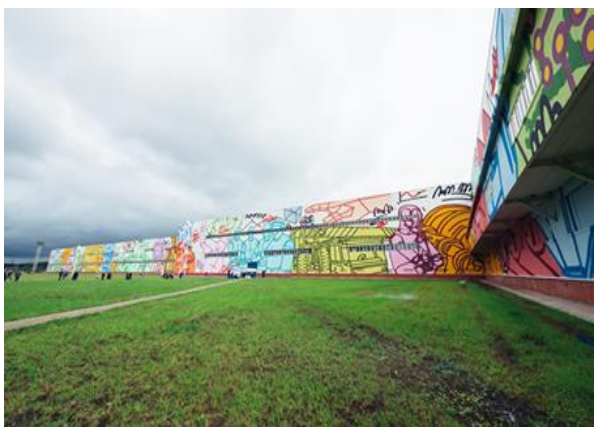

Fig. 5. Russia, the city of Vyksa, the largest wall painting in Russia and in Europe made on the facade of the OMK (United Metallurgical Company) plant, authored by the artist Misha Most. The area of the painting is 10 thousand square meters. Source: N. Volkova.

Source: (https://xn--80ady2a0c.xn--p1ai/18267art-ovrag.html)

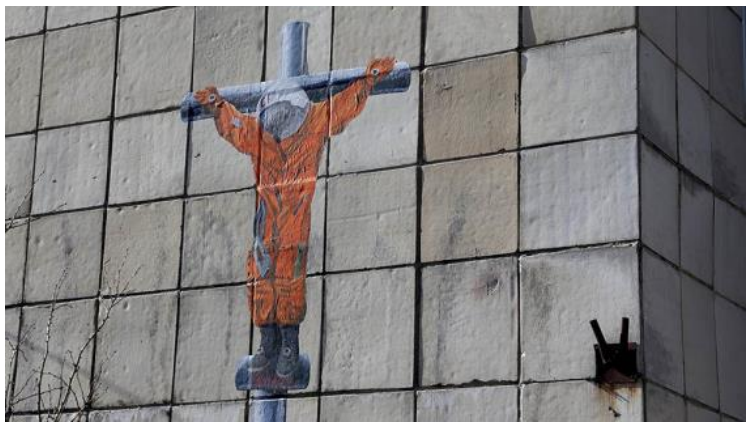

Fig. 6. Graffiti in Ufa (Hanging of Gagarin). Source:(http://sadalskij.livejournal.com/2204436. html) 


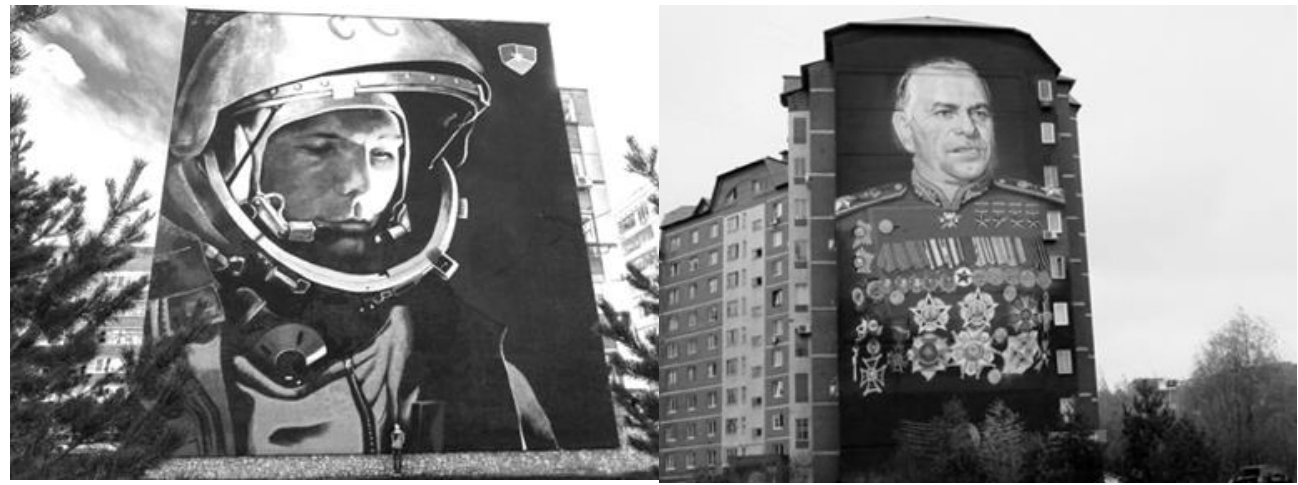

Fig. 7. Graffiti in Ufa (Yu. Gagarin Street). Source: own archives.

Fig. 8. Graffiti in Ufa (Marshal Zhukov Street).

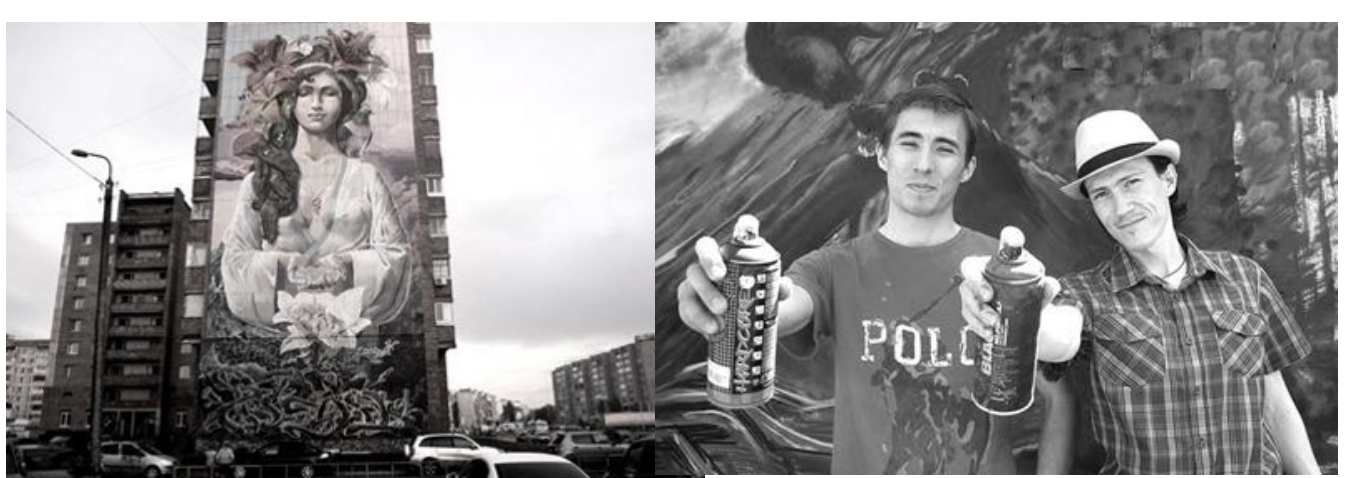

Fig. 9. Graffiti in Ufa (Transportnaya Street). Source: own archives.
Fig. 10. Ufa artists Oleg Kaibyshev and Arthur Audis.

Source: own archives.

As we see, monumental painting is becoming an actual phenomenon on the territory of our city. It gives coloring, originality and individuality to the image of Ufa, emphasizing the importance of our history and its creators. On the photo we see stories that are characteristic of Russian history: Yu. Gagarin and G. Zhukov.

Yuri Gagarin, the first Soviet cosmonaut, is one of the symbols of Russia. The equally important symbol is the Russian commander, the "people's Marshal" Georgy Zhukov, whose portrait is located on one of the buildings at the same street. Grustina (2015) believes that in the Russian consciousness Zhukov became the embodiment of the Christian Saint George the Victorious as a manifestation of the archetype.

Other graffiti contains existential subjects as a reflection of the actual youth problems: love, movement, youth itself, and acute satire on reality. Graffiti is an explosion of emotions, a palette of feelings and an expression. Tsygina in her work "Graffiti - the art of the turn of the centuries" characterizes it as "a kind of anonymous visual dialogue of the writer with other members of society". On other streets, the walls of buildings are full of different images, pleasing and attracting attention of passers-by. In this direction of art, the NAMES appear which become known far beyond graffiti communities. So, for example, Oleg Kaybyshev and Arthur Audis became famous among Ufa graffiti artists (Valitova, 2015). Jean-Michel Basquiat is among the world-known names.

If we compare Ufa with St. Petersburg in this respect, we can notice the similarity of the themes and techniques of work execution, which also demonstrates the globalization of all processes in our life, even in such an individualistic sphere as street art. 


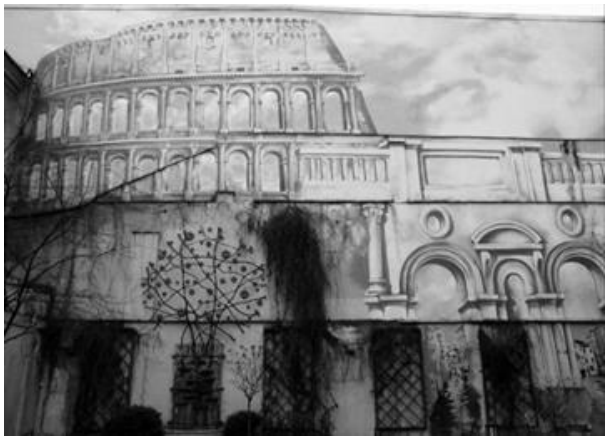

Fig. 11. Graffiti in St. Petersburg (Italianskaia Street).

Source: own archives.

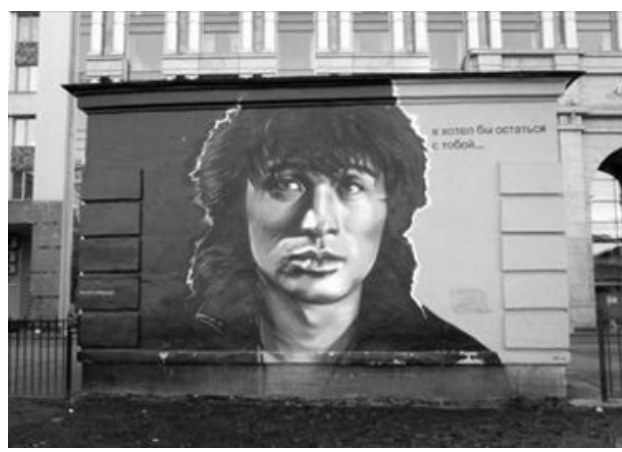

Fig. 13. Graffiti in St. Petersburg (Mayakovsky Street).

Source: own archives.

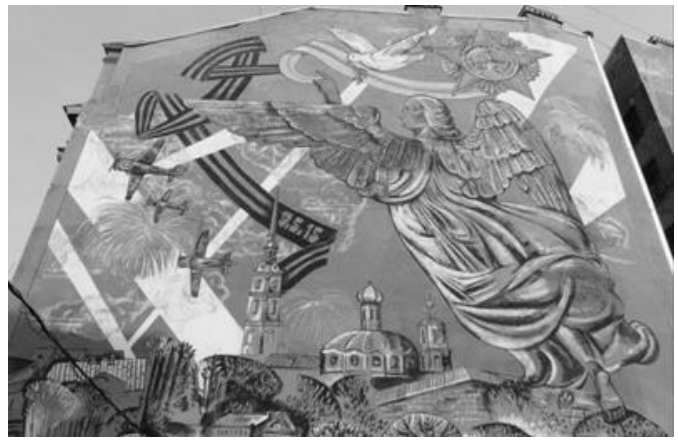

Fig. 12. Graffiti in St. Petersburg (Malyi Prospect). Source: own archives.

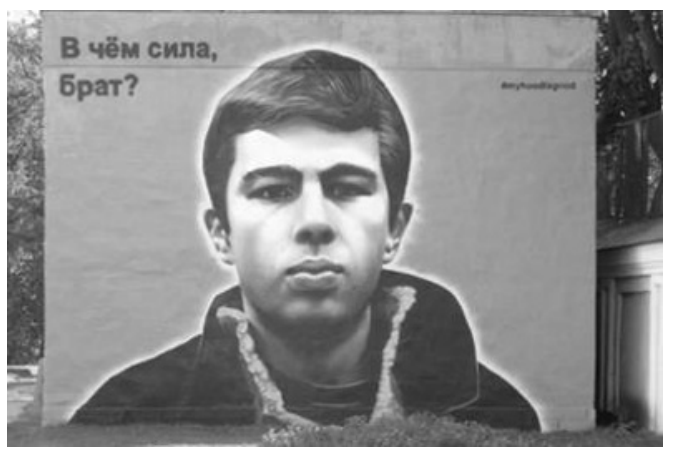

Fig. 14. Graffiti in St. Petersburg (Alexander Nevsky Square).

Source: own archives.

Streets of St. Petersburg do not differ mentally from any other Russian city. Street art captures significant names for Russian society, such as Victor Tsoi and Sergei Bodrov the Junior. By what did these young people deserve to perpetuate themselves in street art?

Victor Tsoi is a rock musician, poet, artist and actor. Russian and Korean blood, the West and the East combined in him. Spirituality, music, and creativity in general, the image that he carried in himself represented a symbiosis of West European rock and national Russian cultures with an eastern essence. His work fell on the difficult 80 -ies of the $20^{\text {th }}$ century, when there was still an "iron curtain" that closed the Soviet Union from the West, but a desire to open it was already in the air. And one of Tsoi's songs "We are waiting for changes" became a kind of a message of life renewal, sounding in almost every heart.

Sergei Bodrov the Junior is the son of the famous Russian filmmaker Sergei Bodrov the Elder, a representative of so-called "golden youth" and "Moscow majors". He defended his Candidate of Science thesis in art criticism. However, in essence, by avocation, Sergei Bodrov the Junior is a Man. Having brilliant opportunities to live carefree, he considered it necessary to work. He played enough roles in complex films, touching the fate of vast majority of people in our country. Bodrov the Junior said that the role for him is an act that he does. And each role was not just played, but lived by him. In each role he carried the Russian mentality with its eternal ideals of good, helping the weak, loving his neighbor, the classic desire for justice and truth, and the unshakable ties of kinship. (1989):

Both of these guys died young, becoming the personification of Viktor Tsoi's poems

"And we know that it has always been so, 
That those are loved more by fate,

Who live by the laws of others,

And who are to die young ..."

The aim of street art here is also obvious. Some works show, for example, the desire to perpetuate the memory of famous people in Russia and the important dates and events.

Let us draw attention of the reader to the fact that graffiti is a purely urban phenomenon. Having emerged in the ancient world as a form of individual perception of the surrounding world, now graffiti acts as a form, inter alia, of personal self-expression. In this article we have already said that modern graffiti is a palette of emotions, feelings, and expressive existence, peculiar to the young people. It is the modern city that is the focus of mad speeds. In this focus of speed, the seething thirst for life of the youth and the phenomenon of alienation collide. The dialectic of this contradiction determines the emergence and development of graffiti as a form of self-expression shaped as street art, or as it is sometimes called, underground art. It manifests itself in everything: in plots, technique of performance, and forms of representation, etc. The subjects of graffiti given in this article are, of course, not exhaustive, but rather illustrative. The military history of Russia is reflected in the portrait of G. Zhukov. The civil history of the Soviet period is represented by a portrait of Yuri Gagarin. And then we see the portrait embodiment of the idea of the modern "Madonna", graceful soft lines of open palms, sloping shoulders, a slightly translucent body, echoing the Madonna of Raphael and Leonardo. The portrait of V. Tsoi, a representative of the underground (Ferreira, 2017), is a portrait of a singer of the era of change, which the humanity eternally craves. On the streets of megalopolis we see black and silver graffiti with flying bikers' motorcycles, colorful, full of joys of life, glades with red poppies and white and yellow daisies. The portrait of Sergei Bodrov the Junior is not just an image of the hero of a wonderful film. This is a philosophical interpretation of the attitude to life: "What is the power, brother?" The power is in the truth, but the truth is in urban reality, in a direct look at the contradictions that life confronts us with. Where the everyday existence of an individual is emotionally and communicatively overloaded and most urban residents tend to live on the principle of "Not to get emotionally involved". The eclecticism of this genre is manifested in colors: from black and white to striking colors; in forms: portraits, landscapes, posts; in subjects: from everyday life to social protest.

\subsection{Graffiti as a form of deviation?}

Some graffiti researchers view this phenomenon as a form of deviation (Korovkin and Yakushev, 2011). L.A. Azarova (2009) in her training manual "Psychology of Deviant Behavior" considers graffiti as a kind of vandalism: "Thus, vandalism in general and graffiti as one of the types of vandalism are considered as a form of teenage youth deviation and delinquency".

To answer the question of whether graffiti is a manifestation of deviation, one should first turn to an understanding of this word. In Latin, deviatio means deviation. S. Ozhegov (1985) defines deviation as "fluctuation from the right direction under the influence of some causes". On the one hand, deviance is considered as the level of specificity of an individual or a group of people, on the other, these are differences in the social structure and the behavior of individuals determined by this; thirdly, deviance is understood as the interaction between the actions of the individual and the reaction of the society to them; fourthly, deviance is treated as a result of education (Davidson, 2006).

Thus, revealing the essence of the concept of "deviation", we come to the conclusion that this is a deviation from the standard, from the norm. But human development, the individual's life activity is always nonlinear. Does this mean that any person is a deviant? From the socio-philosophical point of view the answer is yes, this is so. 
Indeed, if we consider graffiti in a narrow aspect, as a violation of the original urban background, then this is a deviation. Many other authors (Tompson et al., 2012) associate graffiti with various forms of vandalism in transport or in municipal areas (Halsey and Young, 2002).

A. Belkin (2012) in his thesis studies graffiti as a form of deviation, calling this activity as quasi-communication. He assesses graffittists as more aggressive than other members of the society, arguing that through drawing, the graffiti writers resolve both intrapersonal and interpersonal conflicts (Belkin, 2012).

As comments on Belkin's reasoning on deviation, we would like to quote a prominent thinker Ortega y Gasset: "To live means to be completely immersed in the mysterious. On this initial and pre-intellectual riddle a person reacts, activating his intellectual tools, and above all, the imagination. He creates the mathematical world, the physical world, the religious world, and the worlds of morality, politics and poetry, which really are "worlds" because they have an image ... "(Ortega y Gasset, 1997).

Indeed, life itself is a combination of reality and fantasy. Most people have the need for self-actualization and for self-expression (Maslow, 2006). We all try to self-actualize ourselves in various forms: in scientific discoveries, in work, in the family, and in multifaceted creativity. But we do not call these forms of self-expression quasicommunications. One can make a drawing on paper and leave it at home, for oneself. And one can take this picture out of his/her personal space, into the open spaces of city streets. A graffiti artist like any creative person tries to express his worldview, emotional state through drawing and share with others. Most parents, who have children, in our opinion, have experienced a period when children drew everywhere where their curious eyes fell. Watching the growth of our children, as well as the children of our friends, we came to the conclusion that for a child there are no borders and prohibitions, they live in a single, syncretic world. Therefore, children's drawings on any surface are an immanent form of materializing their ideas and their worldviews. No psychologist will call this children's creativity a deviation. Creativity of the artist, drawing on a fabric canvas, is not classified by society as a deviation. For a graffiti artist, wide spaces of the city quarters are a canvas, where he can talk with the society in a colorful, fantasy language.

However, life itself is a complex and controversial phenomenon to uniquely assess the work of graffiti artists. As we earlier noted in our article, the unification and universalism that accompany globalization, include inter alia the absence (or maximum restraint) of emotions, colors, and life. Graffiti with which we associate the social youth protest against boredom, dullness and lifelessness, is indeed a deviation. But this is the deviation that dialectically breaks the narrow traditional framework and brings the society to a new level of development. Berdyaev (1926) wrote that "God expects from man an anthropological revelation of creativity, hiding from man his way of creativity and the justification of creativity in the name of God-like freedom". The meaning of the above statement of an outstanding Russian thinker allows us referring graffiti to art, which, like other art forms, has different levels, styles, directions, etc.

\section{Conclusions}

7.1. Graffiti should be considered as an art form. In modern interpretation, we can observe its maturity in technological and artistic aspects, as well as the plurality of styles, the diversity and high artistic level of the technique of performance, and the versatility of the subjects.

7.2. As an art form, graffiti is typical for any country since it embodies the mentality of a particular society. Graffiti as street art reflects the specifics of the country's culture, national ideas and priorities, and the people's mentality. 
7.3. Unlike other art forms, graffiti is the art of young people: its bearer, the creator of it is the generation Next. As a form of art, graffiti, being the heir of the underground culture, goes beyond the boundaries of official art workshops, to wide, outside the framework, spaces of the streets.

7.4. In the Russian context, the graffiti story line performs two main functions. On the one hand, it refreshes and visually facilitates the architectural appearance of modern Russian cities, including the remaining gray, monumental legacy of the Soviet period. On the other hand, it fosters the formation of patriotic consciousness, using as subjects heroic pictures of Russian history.

7.5. Our analysis of one of the segments of modern global culture, graffiti, graphically illustrates the dialectic nature of social development. Graffiti as an extra-national and metasocial phenomenon appears simultaneously as a manifestation of universalism of the global socio-cultural tendencies, and the expression of eclecticism of the new forms of the modern city. Thus, the basic cultural values are preserved - they are outside of time. At the same time, traditional values, modified and mutated, are updated in accordance with the trends of social history, and determine social progress.

\section{Acknowledgments}

The authors of this article are sincerely grateful to Professor Vadim Strielkovsky, Doctor of Economics, Director of the Prague Institute for Advanced Studies, Professor of Prague Business School, and to the staff of International Research Center "Scientific Cooperation", Rostov-on-Don, Russia, for organizing refresher courses "Publication activity in the European Union: from theory to practice", which were useful for writing this work.

\section{References}

1. O. M. Ivanova, E. A. Guriev, L. M. Bilalova, The Symbol of Science. Monthly International Scientific Journal, 11, 2 (2015)

2. N. A. Tsygina, Herald of MGHPA, 3 (2014)

3. N. Valitova, News Portal ProUfu.ru, 6 (2015)

4. D. S. Korovkin, V. V. Yakushev, Actual problems of criminalistics and forensic examination. Theses of the regional scientific-practical conference (2011)

5. L. A. Azarova, Psychology of deviant behavior: L. A. Azarova \& V. A. Syatkovsky (GIUST BSU, Minsk, 2009) 